\title{
Position of delay and delay-associated cues in maze learning
}

\author{
EDMOND E. WILLIS AND J. M. SAWREY, SAN JOSE STATE \\ COLLEGE, San Jose, Calif. 95114
}

Forty-eight rats were run in a multiple $T$ maze, and either immediately reinforced, delayed in the middle of the maze, or delayed at the end of the maze. Cues associated with the position of delay were manipulated. Both delay groups exhibited pre-delay decrements and post-delay increments in performance. Ss delayed at the end of the maze required fewer trials to criterion than $S s$ delayed in the middle of the maze. The data were interpreted as consistent with Amsel's (1958) hypothesis.

Amsel (1958) hypothesized that delay produces frustration, an aversive motivational state, and causes an increment in drive. A secondary form of frustration, fractional anticipatory frustration $\left(r_{f}\right)$, develops over trials through classical conditioning and serves as an inhibitory mechanism. Thus, pre-delay performance suffers a decrement because of the anticipation of frustration, and postdelay performance is facilitated because the delay-produced frustration adds an increment to drive. Wist (1962) proposed that the effects of delay are largely local; that is, the effects of delay are exerted on those portions of the behavior chain that immediately precede and immediately follow the point of delay.

Delay in the middle of a response chain should adversely affect the pre-delay portion of the chain whereas the post-delay portion should be incrementally affected. Delay at the end of a response chain should adversely affect only that portion of the chain immediately preceding the point of delay. Because the consummatory response occurs at the end of the chain, the cues located at that point should become conditioned to the consummatory response. These cues would provide sources of secondary reinforcement and facilitate the learning of the responses that lead to delay. Because the cues in a delay section in the middle of the response chain are further removed, both temporally and spatially, from the consummatory response than are the cues at the end of the chain, the cues at the end should acquire greater secondary reinforcing properties than those in the middle. The effect should be to enhance the conditioning of $r_{f}$ to the reward and to the responses that lead to reward. Therefore, delay imposed at the end of a response chain should result in faster acquisition of a response chain than delay enforced in the middle of a response chain.

Subjects. The Ss were 48 experimentally naive, male, Sprague-Dawley rats, 70 days old at the start of the experiment.

Apparatus. The apparatus used was an eight-unit multiple $T$ maze. The pattern was LRRLRLLR. Each arm of each T was 15 in. long and 4 in. wide; the height of the walls was 12 in. A 14-in. $x$ 4-in. $x$ 15-in. cul-de-sac was attached to the end of each incorrect arm of each section, with the exception of sections four and eight. The stem of section one constituted the start box; the right arm of section eight constituted the goal box. The left arm of section four was constructed so that delay could be enforced in that section. The start box, delay section, and goal box were separated from the rest of the maze by guillotine doors. The entire maze was painted flat gray. Cardboard inserts, painted flat black, were placed inside the delay section or inside the goal box.

Procedure. All Ss were placed on a $23-\mathrm{h}$ food-deprivation schedule, and were given five trials per day for six days pretraining in a straight alley with immediate food reward. After pretraining, Ss were assigned randomly to one of three groups of 16 rats each. One group received immediate reward, another was delayed for $30 \mathrm{sec}$ in the middle of the maze, and the third was delayed for $30 \mathrm{sec}$ in the goal box. Within each group, four subgroups of four Ss each were formed. For one subgroup, both the delay section and the goal box were gray (GG); for another they were both black (BB). A third subgroup had a black delay section and a gray goal box (BG), while the fourth had these reversed (GB).

All Ss were given one trial per day. $S$ was placed in the start box and, after $5 \mathrm{sec}$, the start box door was raised. When $S$ passed through the delay section in the middle of the maze, the door located at the end of that section was lowered, thus dividing the maze into two parts. Ss in the no-delay group
(Group 1) were allowed to run the entire maze to the goal box where they were immediately reinforced. Ss delayed in the maze (Group 2) were delayed for $30 \mathrm{sec}$ before being allowed to run the rest of the maze. Ss delayed in the goal box (Group 3) were allowed to run the entire maze to the goal box, but were detained for $30 \mathrm{sec}$ before food was presented.

The criterion for learning was four errorless runs in five consecutive trials. Errors per trial, errors in the first half of the maze, and errors in the last half of the maze were recorded. Running time from the start box to the delay section, and from the delay section to the goal box, were recorded.

Results. Means were computed for trials to criterion scores and for error scores. Running times were transformed into reciprocals, and means were calculated. Trials to criterion, errors per maze segment, and running speeds per maze segment were treated as a 2 by 2 by 3 analysis of variance design.

Analysis of variance for trials to criterion showed that the three delay groups were different at the .01 level $(F=314.723, d f=47$, $\mathrm{p}<.01)$. Fisher's $t$ test showed that Group 2 required more trials than did Group $3(t=11.698, d f=30, p<.01)$, and that Group 3 required more trials than did Group $1(t=15.385$, $d f=30, p<$ $.01)$. An interaction was found between Groups and Middle Box Color $(F=3.680, \mathrm{df}=47, \mathrm{p}<.05)$, with Group 2 requiring more trials when the middle box cues were black. The effect was greater for Group 2 than for Group 1 ( $t=2.981$, df $=14, p<.01$ ), but not for Group 3. Groups 1 and 3 did not differ.

The analyses of variance for errors and running speed in the first half of the maze showed that the effects of Groups was significant at the .01 level $(\mathrm{F}=58.48$, df $=47, \mathrm{p}<.01$, and $\mathrm{F}=37.69$, df $=$ $47, \mathrm{p}<.01$, respectively). Group 2 made more errors and ran slower than did either Group $1(t=4.692, \mathrm{df}=30, \mathrm{p}<.01$ : and $\mathrm{t}$ $=8.567, \mathrm{df}=30, \mathrm{p}<.01$, respectively) or Group $3(\mathrm{t}=5.703, \mathrm{df}=$ $30, \mathrm{p}<.01$; and $\mathrm{t}=6.387$, $\mathrm{df}=30, \mathrm{p}<.01$, respectively). Groups 1 and 3 did not differ from each other. All groups ran faster when the middle box was gray $(F=5.28, \mathrm{df}=47, \mathrm{p}<.05)$.

The analyses of variance for errors and running speed in the last half of the maze showed that the effect of Groups was significant $(F=50.55, \mathrm{df}=47, \mathrm{p}<.01$, and $F=73.83$, df $=47, p<.01$, respectively). Group 3 made more errors and ran slower than 1 ( $t$ $=10.15, \mathrm{df}=30, \mathrm{p}<.01$, and $\mathrm{t}=4.46$, $\mathrm{df}=30, \mathrm{p}<.01$. respectively), while Group 1 performed poorer on both measures than did Group $2(t=4.38, \mathrm{df}=30, \mathrm{p}<.01$, and $\mathrm{t}=7.43, \mathrm{df}=30$, $\mathrm{p}<.01$, respectively). All Groups made more errors when the middle box was gray $(F=10.76$, df $=47, p<.01)$. A Groups by End Box by Middle Box interaction was found $(F=4.76, \mathrm{df}=47$, $\mathrm{p}<.05$ ).

Discussion. The results of this experiment support the conclusion that the acquisition of a maze habit is at least partially determined by the position at which delay is enforced. The data may be interpreted as being consistent with Amsel's (1958) hypothesis that delay produces an aversive motivational state that serves to inhibit pre-delay performance through the anticipation of frustration, while facilitating post-delay through an increment in drive. The effects of position of delay may be related to the post-delay increment in drive. When Ss are delayed in the middle of the maze, at least part of the increment may be dissipated in running to the goal box. When delay occurs in the goal box, however, the only post-delay response available to $S$ is the consummatory response. The general effect is that the consummatory response accurs under heightened drive. The heightened drive increases the value of the consummatory response, and facilitates the conditioning of $\mathrm{r}_{\mathrm{f}}$ to the responses that are made and to the reward. Since delay at the end of the maze resulted in fewer trials to criterion than did delay in the middle of the maze, it may be concluded that the conditioning of $\mathrm{r}_{\mathrm{f}}$ occurred at an earlier point in acquisition training for Ss delayed in the goal box than for those delayed in the middle.

That the effects of delay are local, as proposed by Wist (1962), is supported by the data for errors and running speed per maze segment. Even though the entire maze preceded the point of delay for Group 3, the Ss in that group did not differ from Group 1 on either measure in the first half of the maze.

The finding that Group 2 required more trials to criterion when the middle 
box was distinctive is consistent with Amsel's hypothesis. That is, Ss delayed in the middle of the maze required more trials to criterion when running toward a distinctive delay section. The finding that all groups ran faster in the first half of the maze is probably due to the pretraining procedures rather than to the anticipation of frustration. Ss were pretrained in a gray runway. The introduction of the distinctive black, cardboard delay section was, therefore, a novel and perhaps fear-producing situation. This effect did not occur for goal-box cues since the novel stimuli there were associated with food reward.

\section{REFERENCES}

AMSEL, A. Drive properties to the anticipation of frustration. Psychol Bull., $1958,55,102-119$.

WIST, E. R. Amount, delay, and position of delay of reinforcement as parameters of runway performance. J. exp. Psychol 1962, 63, 160-166. 